\title{
VOZES DA PERIFERIA EM MASTROS VOTIVOS DE OUTRORA E MASTRO DO DIVINO
}

Luiz Rodrigo Brandão Pinheiro ${ }^{1}$

Maíra Oliveira Maia ${ }^{2}$

Resumo: O presente trabalho tem por objetivo analisar as narrativas "Mastros Votivos de Outrora", de De Campos Ribeiro e "Mastro do Divino" de Bruno de Menezes. Tal análise parte da observação das produções de ambos e sua relação com o social, a partir do envolvimento destes com a cultura popular e suas representações, tomadas por matéria prima, partindo do envolvimento do grupo ao qual faziam parte, a Academia do Peixe Frito. Deste modo dividiram-se os textos dando destaque a pontos específicos que permitiram realizar as abordagens propostas a partir dos estudos de Bourdieu (2004), Hall (2016), Motta (2013) e outros que complementarão as discussões deste trabalho.

Palavras-chave: Narrativa. Cultura. Social. Grupo.

\section{INTRODUÇÃO}

A proposta do trabalho a seguir teve sua origem nos encontros do grupo de pesquisa do PPGCLC 3 . Criado em 27 de outubro de 2016, nomeado Academia do Peixe Frito. Rebeldia e Negritude no Norte do Brasil é um grupo coordenado por Paulo Jorge Martins Nunes ${ }^{4}$ e Vânia Maria Torres Costa ${ }^{5}$. Trata-se de um grupo de pesquisa acadêmica certificado e sediado pela UNAMA- Universidade da Amazônia. Seu objetivo principal é realizar pesquisas sobre a temática da negritude por meio de estudos das obras de escritores paraenses que compunham um conjunto de literatos e intelectuais atuantes no início do século XX. Hoje, o grupo tomou caráter interinstitucional, visto que uma das coordenadoras transferiu-se para a UFPA.

O grupo de pesquisa surgiu da necessidade de compreender e ressignificar o acervo literário produzido por personalidades importantes da literatura brasileira produzida no Pará. Entre estes destacam-se os escritores, De Campos Ribeiro, Jaques Flores, Abguar Bastos, Rodrigues Pinagés e os dois mais destacados por

\footnotetext{
${ }^{1}$ Mestrando do PPGCLC-(UNAMA, 2019); integrante do grupo de estudos e pesquisa Academia do Peixe Frito (UNAMA/UFPA);

${ }^{2}$ Doutora em História (UFPA, 2017), Professora na Universidade da Amazônia (UNAMA).

3 Programa de Pós-Graduação em Comunicação, Linguagens e Cultura da Universidade da Amazônia.

${ }^{4}$ Doutor em Letras- Literaturas em Língua Portuguesa (PUC- Minas Gerais, 2007). Membro do corpo docente do PPGCLC-UNAMA.

${ }^{5}$ Doutora em Comunicação pela Universidade Federal Fluminense(UFF). Professora Adjunta e vicecoordenadora da Faculdade de Comunicação da universidade Federal do Pará (UFPA).
}

Revista de Letras JUÇARA, Caxias - Maranhão, v. 03, n. 02, p. 188 - 199, dez. 2019 | 188 
suas produções: o romancista Dalcídio Jurandir e o poeta Bruno de Menezes (1896/1963), o líder do grupo.

Apontado por aqueles de seu tempo, por críticos e estudiosos posteriores, Bruno de Menezes é considerado o ícone do movimento modernista no Pará. Bruno de Menezes é reconhecido como o líder da APF- Academia do Peixe Frito, grupo no qual o poeta produziu e compartilhou a maior parte de seus textos que incluem poemas, estudos folclóricos, e ainda duas narrativas de maior extensão, a novela Maria Dagmar e o romance Candunga ${ }^{6}$.

O engajamento social é a característica mais perceptível na trajetória de Bruno e de seus companheiros de época. De acordo com Berger (2010), a transformação em intelectual orgânico descrita por Gramsci leva em conta as classes ditas subalternas como detentoras do protagonismo. A maior parte destes intelectuais era formado de jornalistas e, por tanto, eram sujeitos que possuíam sempre relações de trabalho em revistas semanais muito comuns em Belém no século XX, dentre elas está a "Belém Nova" criada por Bruno em 1923, revista apontada como uma das primeiras revistas do movimento modernista na região norte, lembrando que neste período histórico as revistas semanais constituíam um suporte de importância fundamental para a divulgação de informações e textos literários.

As análises a serem realizadas aqui partem do diálogo entre os textos Mastros Votivos de Outrora, crônica produzida pelo escritor e jornalista De Campos Ribeiro, que foi publicada no livro Gostosa Belém de Outrora ${ }^{8}$ e o poema de Bruno de Menezes intitulado Mastro do Divino ${ }^{9}$ da obra Batuque.

A interação aqui proposta entre os textos tem por objetivo observar o papel da mulher da periferia como protagonista através da voz de ambos os narradores por meio do discurso poético entendendo a literatura como veículo de resistência e crítica social. Para realização das abordagens, tomar-se-á por fundamentação teórica os textos de Motta (2013), Hall (2016), Raymond Willians (2011), Bourdieu (2004), Berger (2010), entre outros.

\footnotetext{
${ }^{6}$ Notas de Francisco Paulo Mendes e Maria Anunciada Chaves em prefácio do livro Obras Completas de Bruno de Menezes, volume 3,SECULT, Belém, 1993.

${ }^{7}$ Revista fundada em Belém do Pará em 15 de setembro de 1923. Circulou até 15 de Abril de 1929, criada e dirigida por Bruno de Menezes.

${ }^{8}$ Livro de crônicas publicado pela primeira vez em 1942.

${ }^{9}$ Poema do livro Batuque publicado pela primeira vez em 1931.

Revista de Letras JUÇARA, Caxias - Maranhão, v. 03, n. 02, p. 188 - 199, dez. 2019 | 189
} 


\section{UM GRUPO DE VELHOS NOVOS}

Em sua tese de doutorado, o pesquisador Aldrin Figueiredo ${ }^{10}$ faz uma exemplificada apresentação do início do século XX em Belém do Pará, período histórico de extrema importância para a compreensão do movimento modernista na região norte. É interessante que se ressalte o significado simbólico da frase inicial desta sessão, pois como bem observa o pesquisador citado anteriormente, os intelectuais intitulados "Os Novos" eram homens de uma idade que não Ihes permitia a juventude como característica física. Mas, independentemente da idade, o espírito inovador e a perspectiva da mudança e da busca pela identidade cultural desprovida de roupagens idealizadas fizeram deste grupo de literatos, poetas e demais intelectuais o grupo responsável pela diferença na produção literária do Norte do Brasil.

Considerando que os membros da Associação dos Novos viveram a transição do século XIX para o XX, fica em evidência que estes eram conhecedores da história e do que se escondia por detrás desta. Logo, a história se fez desde o princípio a matéria prima de suas produções. O Modernismo teve seu início no Pará sob a pauta histórica marcada por um sentimento de crítica às incoerências idealizadas. "Era hora de rever a história antiga do Grão Pará, forjada a distância da trajetória brasileira [...]" (FIGUEIREDO, 2001, p.190).

Deste modo, o Modernismo pode ser apontado como um revisor da história por meio da literatura, visto que havia um conflito transferido para a literatura, porém materializado por tensões políticas estabelecidas por uma questão geográfica apoiada por relações de poder. Assim, diante do exposto, compreende-se que o grupo partilha de um sentimento de autoafirmação da identidade. Cabe então estabelecer um comparativo com as colocações de Berger (2010) ${ }^{11}$ a respeito da pesquisa em comunicação na América Latina.

Embora a autora trate especificamente da comunicação, sua forma contextual permite uma melhor observação das propostas do movimento aqui analisado. Segundo Berger (2010), a produção de conhecimento na América Latina é resultado da necessidade provocadora em prol das demandas políticas e sociais. Para ela,

${ }^{10}$ Aldrin Moura de Figueiredo- Professor da Faculdade História da Universidade Federal do Pará. Doutor em História (UNICAMP-2001).

${ }_{11}$ Christa Berger-Professora aposentada da Universidade Federal do Rio Grande do Sul. Formada em Comunicação Social- Jornalismo pela PUCRS (1979). É Professora de Teorias da Comunicação e disciplinas de Jornalismo na UFRGS.

Revista de Letras JUÇARA, Caxias - Maranhão, v. 03, n. 02, p. 188 - 199, dez. 2019| 190 
este fenômeno não se resume ou surge de questionamentos científicos, haja vista que a motivação neste caso parte da perspectiva de um impacto social, característica presente nas produções de todos os membros da associação dos novos.

A autora atenta para o fato de que a existência de uma dependência estrutural traz ao mesmo tempo uma cultura de submissão e um propósito de resistência, logo compreender essa dualidade é o primeiro passo para entender o que de fato estava ocorrendo, e mais ainda, é necessário colocar em primeiro plano a relação do que está sendo abordado com o contexto da época a qual está se analisando, algo que fora realizado desde o início deste tópico.

Considerando a "Belém Nova" como pioneira do Modernismo na região Norte, é possível dizer que sua história e principalmente os dados que thes foram confiados assumem extrema importância para que se tenha hoje a dimensão do que fora produzido pela Associação dos Novos. Assim, após uma breve introdução sobre o modernismo em Belém, iniciaremos a abordagem das obras de Bruno de Menezes e De Campos Ribeiro.

\subsection{MASTROS INTERCESSORES}

Embora se tratem de dois tipos textuais diferentes, uma crônica e um poema, o que é necessário assimilar é que ambos são narrativas, e sendo narrativas são representações das ações humanas através da arte, conceito de mimese descrito por Aristóteles em sua arte poética. Sendo assim, as duas narrativas a serem analisadas são representações que configuram processos miméticos que tal como Gebauer e Wulf (2004) citados por Motta, afirmam se tratar de [...] "processos imprescindíveis para a relação do homem com a natureza, a cultura e a sociedade [...]" (MOTTA, 2013, p.72).

Por estas questões se escolheu trabalhar com textos narrativos a fim de verificar as comunicações anexadas ao fazer poético. Contudo, vale ressaltar que não se trata de uma análise puramente literária, haja vista que este trabalho se propõe a observar o conteúdo social e histórico da narrativa a partir dos pressupostos da narratologia que: [...] se revela não como um ramo das ciências da linguagem, nem como um desdobramento da teoria literária, mas como uma forma 
de análise do campo de estudo antropológico, porque remete à cultura da sociedade e não apenas às suas questões ficcionais (MOTTA, 2013, p. 80).

Com isso, o autor explica que analisar uma narrativa significa também ir em busca dos significados através da cultura, para que de uma forma mais abrangente se constitua um mecanismo de análise social, e não somente textual, para isso Motta elabora um estudo da narrativa a partir de três planos de análise que são: plano de expressão, plano de conteúdo e plano da metanarrativa.

De um lado é defendida a compreensão de cunho mecânico da análise do texto que segundo o mesmo autor é elemento crucial, porém não é suficiente, logo, se faz necessária a busca por além do superficial. Bourdieu (2004) considera mais relevante os modelos que, tais como fora proposto acima, levam em consideração as questões contextuais nas quais as obras analisadas são postas em diálogo com o mundo social.

Desse modo, a seguir serão analisados trechos das obras literárias em questão, observando os planos de expressão e de conteúdo, assim como a construção das relações de poder dentro do texto narrativo.

\section{DAS ANÁLISES}

A partir daqui, estar-se-á trabalhando diretamente com os trechos julgados pertinentes para o desenvolvimento das abordagens considerando-se que se tratam de narrativas de porte mediano. Para melhor observação destas, utilizaremos dois quadros principais e três citações como a seguinte:

De qualquer maneira, esse Mastro do Divino, como outros, de devoção a são Benedito, por exemplo, ainda erguidos na cidade em épocas e bairros diversos, não conseguiram jamais a popularidade, o prestígio e a tradição logrados por dois outros de outrora, ambos do Umarizal, ambos atraindo romeiros dos quatro cantos de Belém e mais de "Oropa, França e Bahia", se por isso aceitarmos Pinheiro, Mosqueiro, lugares outros aí das redondezas (RIBEIRO, 2005, p. 58).

No excerto acima, o narrador faz uma retomada de informações superficiais a respeito das demais festas, mas salienta que duas festas em especial eram as mais reconhecidas. Contudo é incrementada certa ironia através de um jogo de palavras, estabelecendo comparação de espaços/lugares distantes com localidades regionais. Nota-se uma possível crítica aos indivíduos participantes em sua condição de 
deslocamento e assim é possível inferir que a equivalência de vocábulos ocorre para mascarar ou amenizar sua intencional equivalência semântica.

O deslocamento propõe numa perspectiva socioeconômica um meio de empoderamento ocasionado por estar em outro lugar onde não é conhecido. Neste caso poderá haver uma melhor recepção por parte dos sujeitos receptores de prestígio por saber que alguém veio de longe, ao mesmo tempo em que se pode ter do sujeito que prestigia um grau de superioridade alimentado pela posição que ocupa nesse momento.

Trata-se então de uma relação de poder em um campo construído pela ocasião da festa tal como Immacolata cita Bourdieu em seu artigo sobre o campo da comunicação, ao explicar que este define o campo como um espaço social preenchido por vários sujeitos. Portanto, o que faz com que um campo exista são as constantes instabilidades geradas internamente. Em outras palavras, Bourdieu (1997) definira o campo como uma cúpula que embora não seja física, torna-se palco para relações de dominâncias estabelecidas entre seus integrantes sempre a exercer um movimento desigual no que diz respeito ao lugar que cada sujeito ocupa. Isso se reforça com a frase: "Os "Mastros do Umarizal", em verdade, geravam até rivalidades, preferências" (RIBEIRO, 2005, p. 58).

Não só as festas de mastro, mas também as festas de boi bumbá ${ }^{12}$ são representadas por Bruno de Menezes e De Campos com a característica recorrente das rivalidades, como bem retrata o filme "Um dia qualquer" ${ }^{13}$ de Líbero Luxardo, em uma cena que retrata o encontro de dois grupos que resulta em briga. Chama-se a atenção para os créditos do filme cujas toadas de boi são de autoria do poeta Bruno de Menezes. "As festanças do divino no Pará, diga-se de passagem, nunca se revestiram do esplendor, da pompa característica ainda em uso no Maranhão, onde se trasladaram com outras manifestações folclóricas" (RIBEIRO, 2005, p. 59).

Polistchuk (2003) ao citar Gramsci, complementa que este definia o folclore como componente importante da cultura popular em suas colocações a respeito dos mecanismos de poder, que levavam em conta as práticas de negociações e outros fatores de caráter mediador. Embora hoje alguns estudiosos considerem o termo

\footnotetext{
12 Boi bumbá - manifestação da cultura popular- dança composta de personagens humanos e animais a representar uma lenda sobre a morte e ressureição de um boi.

${ }^{13}$ Um dia qualquer - Filme de Líbero Luxardo lançado em 1965, narra o dia a dia da cidade de Belém da época em que fora produzido a partir da história dos personagens Carlos e Maria de Belém.
}

Revista de Letras JUÇARA, Caxias - Maranhão, v. 03, n. 02, p. 188 - 199, dez. 2019 | 193 
folclore como portador de significações pejorativas ou preconceituosas, cabe lembrar que no contexto que estes textos foram produzidos, os estudos da época tinham uma visão distinta e não se pode deixar de levar em conta esse fator contextual.

Nota-se que há preferência por parte dos autores em trazer para o texto as manifestações culturais. De acordo com Polistchuk (2003) ${ }^{14}$, em sua abordagem sobre o Paradigma culturológico, nas proposições dos estudos culturais iniciadas por estudiosos como Barthes ${ }^{15}$ e Umberto $\mathrm{Eco}^{16}$, existe uma relação dinâmica que aproxima a padronização cultural ao domínio da cultura, dentro de uma perspectiva inovadora, e que esta relação se equipara aos processos hibridizantes contidos no diálogo entre o real e o imaginário, relação de intensa importância à observação de um objeto narrativo.

Segundo Polistchuk, na perspectiva do paradigma culturológico, as produções da indústria da cultura passam a ter maior atenção em relação ao estudo dos meios de comunicação. A revista "Belém Nova", tal como os livros produzidos pela Associação dos Novos são meios de comunicação dos ideais propostos por aqueles, mas vale dizer que a questão antropológica é o ponto que gera maiores questionamentos na busca pela construção dos sentidos.

Festa tradicional da cidade a de mestre Martinho. Um velho artista da terra, o espanhol Estrada, fixou-a mesmo num quadro existente na prefeitura, tela hoje de significativo valor. [...] Ora, a festa de tia Ana longe estava, apesar de famosa do brilho da do velho Martinho João Tavares. Mais modesta, não atraia as gentes de bairros distantes (RIBEIRO, 2005, p. 60).

A esta relação de oposição poder-se-á estabelecer um breve diálogo com as seguintes explicações sobre a definição inicial do campo que, "É a estrutura das relações objetivas entre os diferentes agentes que determina o que eles podem e não podem fazer. Ou mais precisamente, é a posição que eles ocupam nessa estrutura que determina ou orienta, pelo menos negativamente, suas tomadas de posição" (BOURDIEU, 2004, p. 29). De acordo com o exposto, pode-se inferir que a diferenciação que o narrador realiza em relação ao grau de prestígio entre as festas

\footnotetext{
14 Ilana Polistchuk - Mestra em Comunicação Social pela Escola de Comunicação da UFRJ.

${ }^{15}$ Roland Barthes - Escritor, sociólogo, crítico literário, semiólogo e filósofo francês.

${ }^{16}$ Umberto Eco - Nascido em janeiro de 1932 na cidade de Alexandria na Itália. Dedicou-se aos estudos de Literatura e Filosofia na Universidade de Turim.
}

Revista de Letras JUÇARA, Caxias - Maranhão, v. 03, n. 02, p. 188 - 199, dez. $2019 \mid 194$ 
é uma forma de problematizar a representação em que os personagens são colocados por ele de modo a estabelecer o lugar de fala de ambos.

\section{Quadro1: Diferenças do prestígio das Festas}

\begin{tabular}{|c|c|}
\hline Mastros Votivos de Outrora & Mastro do Divino \\
\hline $\begin{array}{l}\text { Os novos juízes do mastro } \\
\text { entenderam de abafar o arraial de } \\
\text { mestre Martinho e fizeram deslumbrante } \\
\text { "féerie", [...] onde até as centenárias } \\
\text { mutambeiras se vestiram de luz, da raiz } \\
\text { à copa esgalhada e farta. Creio que foi } \\
\text { essa a primeira vez que um arraial de } \\
\text { festa suburbana brilhou de luz elétrica, e } \\
\text { que luz! [...] } \\
\text { (RIBEIRO, 2005, pág. } 61 \text { ) }\end{array}$ & $\begin{array}{l}\text { A tia Ana das palhas quer música e baile } \\
\text { No dia em que o mastro vai ser } \\
\text { derrubado } \\
\text { A dona do santo derruba o seu mastro, } \\
\text { Soltando foguetes cantando toadas } \\
\text { Dos sambas do engenho... } \\
\text { (MENEZES, 2015, pág.40) }\end{array}$ \\
\hline
\end{tabular}

(BRANDÃO, 2019)

Nota-se que se trata de um mesmo acontecimento narrado, contudo há uma significativa distância entre a comunicação feita por ambos os narradores. Sabe-se que em se tratando de dois estilos de escrita diferentes, o tratamento do texto deverá, embora não obrigatoriamente, ser apresentado de forma diferenciada. Contudo, observa-se que cada narrador atribui a sua respectiva personagem um status.

No primeiro, o narrador explica que a festa terá uma boa estrutura pela primeira vez, enquanto que no segundo ele deixa suspensa a possibilidade de o leitor inferir se o verbo querer representa um desejo ou uma realidade da personagem. Não se está dizendo aqui que os dois textos devam manter semelhanças obrigatórias, ou que devam ter um compromisso com a realidade, visto que por se tratar de textos literários o que vale é a convenção da verossimilhança e não de uma verdade.

Em resposta a isso, pode-se buscar a seguinte colocação a respeito da autoridade do narrador: "É ele quem dispõe do poder da voz para organizar, encadear, posicionar, hierarquizar, dar ao seu interlocutor as pistas e instruções de uso por meio das quais indica como pretende que seu discurso seja interpretado" (MOTTA, 2013, p. 211).

Revista de Letras JUÇARA, Caxias - Maranhão, v. 03, n. 02, p. 188 - 199, dez. 2019| 195 
Assim, pode-se inferir que esta opção narrativa serve para enfatizar a liberdade proporcionada ao leitor por meio de sua interação com o texto. Portanto, se reconhece que no texto literário, embora ficcional e criado com objetivos baseados em perspectivas artísticas voltadas para o entretenimento, existe uma intencionalidade que se manifesta a partir das diferentes interpretações dos interlocutores.

No ano seguinte, porém ninguém soube porque os juízes se desinteressaram do mastro da santíssima trindade, da tia Ana, do resto. E o mastro subiu, é certo, mas só teve alumiando as noites tristes, de ladainha sem orquestra[...] com meia dúzia de lamparinas fumarentas[...] (RIBEIRO, 2005, p. 61).

Após a proposta do engrandecimento da personagem, o narrador retoma sua observação questionando a ausência do prestígio que lhe fora dado no ano anterior, e segue apresentando o empobrecimento característico de uma situação social desfavorecida financeiramente. Cabe refletir sobre a tensão entre grupos existentes, nos quais os "juízes" representam os detentores de poder que podem exercer sua influência sobre aqueles que estão abaixo deles em um viés hierárquico construído pela sociedade e a "Tia Ana das Palhas" que representa o grupo diretamente afetado pelas ações dos maiores.

Toda essa reflexão permite contextualizar as narrativas aqui tratadas a partir das abordagens de Stuart Hall ${ }^{17}$ e pode-se atribuir ao autor e consequentemente aos narradores de ambos a preocupação com os menos favorecidos, pois de acordo com Hall (2003), todo signo quando separado do contexto social, ou seja, descontextualizado das problemáticas políticas e culturais, tende a resumir-se em alegoria e passa então à condição de objeto puramente filológico, ou neste caso converge em arte pela arte. Em outras palavras não se trata apenas de uma representação simbólica.

\section{Quadro2: Aproximações no desfecho}

\begin{tabular}{|r|l|}
\hline Mastros Votivos de Outrora & \multicolumn{1}{|c|}{ Mastro do Divino } \\
\hline Velha Ana das palhas morria & $\begin{array}{l}\text { E a tia Ana das palhas que benze põe } \\
\text { cartas faz banhos de sorte, rezando } \\
\text { acendendo três velas sagradas, pede à }\end{array}$ \\
\hline
\end{tabular}

${ }^{17}$ Stuart Hall em - Da Diáspora: identidades e mediações culturais.

Revista de Letras JUÇARA, Caxias - Maranhão, v. 03, n. 02, p. 188 - 199, dez. 2019 | 196 
não demorou muito a fazer a derradeira viagem: foram cumprir, lá mais perto do divino e da santíssima trindade, sua devoção que fez época no Pará de há cinquenta anos...

(RIBEIRO, 2005, pág. 61) pombinha branca que a conduza sob as asas,

Quando a dona for ao céu ver os festejos do seu santo...

(MENEZES, 2015, Pág. 41)

Nos trechos acima, ambos falam da morte. O primeiro a concretiza, o outro permite que aconteça. De acordo com Benjamin (1987), a morte pode ser interpretada como o ápice do contar do narrador, nela tudo o que o narrador poderia ou não fazer se materializa como prova da sua autoridade enquanto criador da narrativa.

Por estas afirmações de Benjamin (1987), pode-se dizer que ambas as narrativas colocam fim ao narrado de modo a impor seu direito sobre desfecho da história, sem negar ao leitor a possibilidade de atribuir novas significações.

Retomando ao grupo, a Academia do Peixe Frito, entende-se que os literatos, Bruno de Menezes e De Campos Ribeiro, bem como os demais membros do grupo, partilhavam de um ideal de produção estética vinculada ao meio social, e principalmente aos indivíduos historicamente suprimidos pela literatura e pela arte em geral. A Academia do Peixe Frito ou Associação dos Novos constitui um grupo cultural voltado para as questões identitárias, para a cultura popular e para a valorização das manifestações culturais de seu local de origem.

Com base nestas características, é possível compará-los ao conhecido grupo de intelectuais chamado "círculo de Bloomsbury", e a respeito de sua última nomenclatura, pode-se dizer que assim como o Círculo de Bloomsbury o que hoje é chamado Academia do Peixe Frito "pelo mundo externo nunca existiu na forma a ele dada por esse mundo [...]" (WOOLF apud WILLIAMS, 2011).

Assim, todas as possíveis características atribuídas a eles ao longo das pesquisas desenvolvidas dar-se-ão através dos rastros deixados em meio as suas produções. "[...] "Bloomsbury" foi e é usualmente empregado como um termo- em geral abusivo- aplicado a um grupo de pessoas com objetos e características 
bastante imaginárias [...] Nós éramos e sempre nos mantivemos, essencial e fundamentalmente, como um grupo de amigos". (WILLIAMS, 2011, p. 202).

No entanto, é possível inferir que se fossem entrevistados na atualidade, a resposta mais coerente deveria ser semelhante a esta citação de Woolf feita por Williams, uma vez que se nota, através destes textos, diversas possibilidades de diálogo ao tratar de aspectos internos e externos à escrita.

\section{CONSIDERAÇÕES FINAIS}

Em linhas gerais, a análise realizada neste trabalho permitiu observar com maior atenção as propostas estéticas e principalmente ideológicas atribuídas ao texto por seus respectivos autores, pois observou-se que a personagem "Tia Ana das Palhas" aparece em ambas as narrativas como um símbolo de representativade da mulher da periferia, vista não somente como vítima da sociedade, mas como aquela que deve ser protagonizada no texto.

Vale lembrar que também foi possível constatar que a existência dos grupos culturais como a Academia do Peixe Frito e o Círculo de Bloomsbury, constituem um espaço propício para o exercício da criação literária e para o desenvolvimento de estudos que priorizam o reconhecimento das classes menos favorecidas.

\section{THE SUBURB VOICES IN “MASTROS VOTIVOS DE OUTRORA” AND “MASTRO DO DIVINO"}

Abstract: This paper aims to analyze the narratives "Votive Masts of the other ages" by De Campos Ribeiro and "Mast of the Divine" by Bruno de Menezes. This analysis starts from the observation of the productions of both authors and their relationship with the social, from their involvement with popular culture and their representations, taken by important theories, starting from the involvement of the group to which they belonged "Academia do Peixe Frito". Thus, the texts were divided, highlighting specific points that allowed the approaches proposed from the studies of Bourdieu (2004), Hall (2016), Motta (2013) and others authors that will complement the discussions of this work.

Keywords: Narrative. Culture. Social. Group.

\section{REFERÊNCIAS}

BENJAMIN Walter. Obras Escolhidas Magia e Técnica, Arte e Política. São Paulo, Brasiliense, 1987.

Bourdieu, Pierre. Os usos sociais da ciência: Por uma sociologia clínica do campo científico. São Paulo: unesp, 2004. 
HALL, Stuart. Da Diáspora: Identidades e Mediações Culturais. Belo Horizonte, Editora UFMG, 2016.

BERGUER, Christa. A pesquisa em comunicação na América Latina. IN. HOHLFELD, Antônio; Martino, Luiz C; França, Vera V. Teorias Da Comunicação: conceitos, escolas e tendências. Petrópolis-RJ: Vozes, 2010.

MENEZES, Bruno. Batuque. 8.ed Belém, GTR Gráfica e Editora, 2015.

MOTTA, Luiz Gonzaga. Análise Crítica da Narrativa. Brasília, Editora UNB, 2013.

POLISTCHUK, Ilana; TRINTA, Aluizio R. Teorias da Comunicação. Rio de Janeiro. Editora Campos, 2003.

RIBEIRO, De Campos. Gostosa Belém de Outrora. Belém, SECULT, 2005.

WILLIAMS, Raymond. Cultura e Materialismo. São Paulo, Editora UNESP,2011.

FIGUEIREDO, Aldrin Moura de. Eternos modernos: uma história social da arte e da literatura na Amazônia, 1908-1929. Campinas, SP: [s.n], 2001. 